\title{
Qualidade sanitária de sementes crioulas de feijão de corda no agreste de Pernambuco
}

\section{Sanitary quality of cowpea creole seeds from agreste of Pernambuco}

Kedma Maria Pinto $^{1}$, Danilo Araújo de Noronha ${ }^{2}$, Luciana Maia Moser ${ }^{3}$

DOI: https://doi.org/10.52719/bjas.v3i1.3941

\begin{abstract}
RESUMO
As sementes crioulas são definidas como sementes de variedade local ou tradicional, conservadas, selecionadas e manejadas por agricultores familiares, quilombolas, indígenas e outros povos tradicionais. Essas sementes são importantes para a biodiversidade, como material genético adaptado às condições locais, além do seu valor social, cultural e econômico. Além disso, a qualidade dessas sementes é fundamental para manter a produtividade e conservação desse germoplasma. $\mathrm{O}$ objetivo deste trabalho foi avaliar a qualidade sanitária de sementes crioulas de feijão de corda na região do agreste pernambucano. Sementes de feijão de corda foram fornecidas por agricultores da região e a análise da sanidade foi realizada por meio de blotter test. Dessa forma, as sementes foram incubadas em câmara de germinação (BOD) em rolos de papel germitest esterilizados a $25^{\circ} \mathrm{C}$, por um período de 8 dias. Após esse período, as amostras foram analisadas em lupa e microscópio óptico e os patógenos presentes identificados em nível de gênero. Os resultados mostraram que todas as sementes analisadas estavam com algum grau de infestação por patógenos, principalmente por fungos. Os patógenos encontrados com maior frequência foram os pertencentes aos gêneros Aspergillus e Rhizoctonia, seguidos de Botrytis, Fusarium e Alternaria. A infestação de fungos de armazenamento sugere que essas sementes podem estar acondicionadas de forma inadequada e a ocorrência de patógenos habitantes de solo, pode sugerir risco de disseminação destes patógenos. Entretanto, estudos mais detalhados são necessários para confirmar essa análise. Nossos resultados ressaltam a importância de maior assistência técnica aos agricultores guardiões das sementes crioulas, bem como o uso de boas práticas no beneficiamento dessas sementes com intuito de melhorar a qualidade sanitária das sementes e assim, controlar a disseminação de possíveis patógenos, garantindo a conservação desse patrimônio genético para as gerações futuras.
\end{abstract}

Palavras-chave: Agroecologia. Análise sanitária. Sementes crioulas. Vigna unguiculata

\footnotetext{
ABSTRACT

${ }^{1}$ Universidade Federal do Agreste Pernambucano

2 Universidade Federal do Agreste Pernambucano

${ }^{3}$ Universidade Federal do Agreste Pernambucano
} 
Creole seeds are defined as a local seed or a traditional variety, conserved, selected and managed by family farmers, quilombolas, indigenous people and other traditional people. These seeds are important for biodiversity, as genetic material adapted to local conditions, in addition to their social, cultural and economic value. Furthermore, the quality of these seeds is essential to maintain the productivity and conservation of this germplasm. The aim of this work was to evaluate the sanitary quality of cowpea creole seeds in the agreste region of Pernambuco. Cowpea seeds were supplied by farmers in the region and health analysis was performed using a blotter test. Thus, the seeds were incubated in a germination chamber (BOD) on sterilized germitest paper rolls at $25^{\circ} \mathrm{C}$, for a period of 8 days. After this period, the samples were analyzed using a magnifying glass and optical microscope and the pathogens present were identified at the genus level. The results showed that all analyzed seeds had some degree of infestation by pathogens, mainly by fungi. The most frequent pathogens found were those belonging to the genera Aspergillus and Rhizoctonia, followed by Botrytis, Fusarium and Alternaria. The infestation of storage fungi suggests that these seeds may be inadequately packaged and the occurrence of soil-dwelling pathogens may suggest a dissemination risk of these pathogens. However, more detailed studies are needed to confirm this analysis. Our results highlight the importance of greater technical assistance to farmers who are guardians of creole seeds, as well as the use of good practices in seed processing in order to improve the sanitary quality of the seeds and thus control the spread of possible pathogens, ensuring their conservation. genetic heritage for future generations.

Keywords: Agroecology. Health analysis. Creole seeds. Vigna unguiculata

\section{INTRODUÇÃO}

As sementes crioulas são definidas como sementes de variedade local ou tradicional, conservadas, selecionadas e manejadas por agricultores familiares, quilombolas, indígenas e outros povos tradicionais. São consideradas nativas ou tradicionais porque seu manejo é realizado pelos agricultores familiares ao longo dos anos (Brasil, 2003).

A importância das sementes crioulas do ponto de vista genético, se dá pela adaptabilidade às condições de clima e solo desenvolvidas ao longo de gerações e de seguridade, pela autonomia dos agricultores de não usar insumos e sementes comerciais, de grandes empresas do agronegócio, impactando diretamente na renda dos agricultores familiares. Essa dependência pode levar ao aumento da vulnerabilidade social de agricultores envolvidos no processo e na insegurança alimentar e nutricional (Jantara \& Almeida, 2009). Dessa forma, faz-se necessário a valorização dessas variedades crioulas ou tradicionais que favorecem a biodiversidade local, levando a uma maior capacidade de adaptação às condições ambientais locais e que poderiam ser mais adaptadas que as sementes comerciais (Costa et al., 2003).

Além desses fatores, também deve ser levado em consideração o aspecto afetivo e cultural que se relacionam aos povos em várias gerações de agricultores familiares. De acordo 

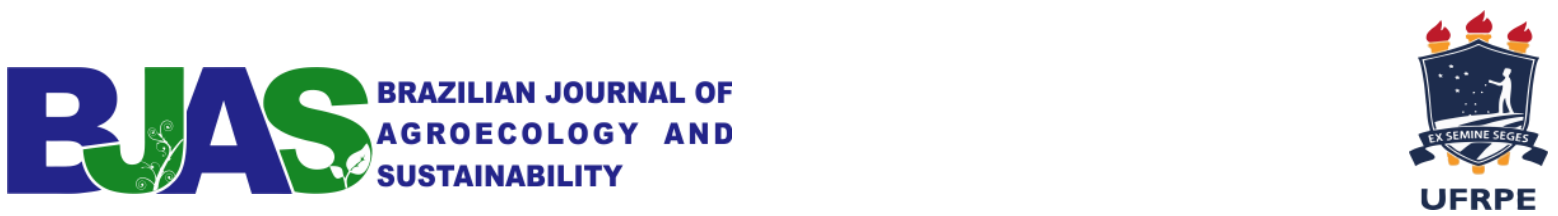

com Petersen e colaboradores (2013), essas sementes recebem várias denominações nas diferentes regiões do nordeste do Brasil, dentre elas: sementes da fartura (Piauí), sementes da resistência (Alagoas e Sergipe), sementes da paixão (Paraíba), etc.

Dentre as principais espécies cultivadas através de sementes crioulas no agreste de Pernambuco, destacam-se o milho (Zea mays) e o feijão, tanto o feijão comum (Phaseolus vulgaris) como o feijão de corda (Vigna unguiculata (L.) Walp.).

O feijão de corda, feijão caupi ou feijão macassar é uma planta originária da África que foi introduzida no Brasil no século XVI. Essa planta pode ser caracterizada como herbácea, anual, de estações quentes e necessita de uma temperatura mínima de $18^{\circ} \mathrm{C}$ para se desenvolver bem, com crescimento ótimo na temperatura em torno de $28^{\circ} \mathrm{C}$ (Leite, 2017).

Essa espécie tem enorme importância na alimentação humana, principalmente na população de baixa renda, devido à sua qualidade nutricional, como excelente fonte de proteínas (17,33 - 18,29\% em média), carboidratos (64,86 - 68,31\%, em média), vitaminas e minerais (Martins et al., 2016), características que demonstram a sua importância, principalmente para agricultura familiar da região do agreste de Pernambuco.

É uma cultura com boa capacidade de fixação biológica de nitrogênio, boa tolerância às condições de baixa disponibilidade de água nos solos, altas temperaturas e relativa tolerância à salinidade, condições comumente encontradas em regiões semiáridas do Nordeste do Brasil. Além disso, boa parte da produção de feijão de corda é realizada por agricultores familiares e comunidades tradicionais (Quilombolas, indígenas etc), que utilizam técnicas de baixa tecnologia, com pouco uso de insumos e agroquímicos (Empresa Brasileira de Pesquisa Agropecuária [EMBRAPA], 2004). Por esses fatores, essa cultura é de grande importância para a região do Agreste de Pernambuco, e dessa forma, é amplamente cultivada (Lima, 2017).

O processo de armazenamento das sementes crioulas é comumente realizado pelos próprios agricultores familiares ou em Bancos Comunitários de Sementes Crioulas que são manipulados por eles e visam à conservação da biodiversidade, através do resgate e multiplicação das sementes (Catão et al., 2010). Dessa forma, os bancos possibilitam a diversificação das amostras, a construção dos estoques de sementes crioulas e a criação de uma rede social para as trocas de sementes e de saberes (Santos et al., 2017). Entretanto, as condições de colheita e armazenamento das sementes nem sempre são adequadas para manter a sua qualidade (Batista et al., 2018), que depende de parâmetros genéticos, físicos, fisiológicos e sanitários. Além disso, as sementes podem abrigar e transportar micoorganismos patogênicos, 

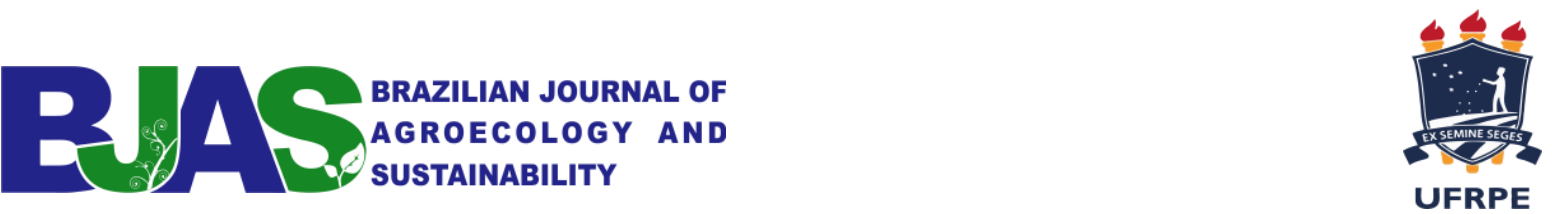

causando danos diretos através da podridão e morte de sementes, produção de fitotoxinas (toxinas que podem afetar humanos e animais), além da possibilidade de transmissão para plântulas ou plantas adultas, sendo responsáveis por doenças que afetam diretamente a produtividade, além disso, do ponto de vista epidemiológico, as sementes se constituem no principal veículo de disseminação de doenças de plantas a longas distâncias, podendo introduzir patógenos em áreas livres da doença (Neegard, 1977; Barrocas \& Machado, 2010). Diante disso, o objetivo deste trabalho foi avaliar a qualidade sanitária de sementes crioulas de feijão de corda coletadas de agricultores familiares na região do agreste pernambucano.

\section{MATERIAL E MÉTODOS}

\subsection{Caracterização da área de estudo}

Foram analisadas amostras de sementes crioulas coletadas de agricultores familiares e banco de sementes nos municípios de Garanhuns, São João e Jucati (Tabela 1), pertencentes à Microrregião de Garanhuns. O clima desta região é classificado, segundo Koppën, como tropical quente e subúmido seco, com intensos eventos de precipitação (As', BDhs' e Cs'a) (Lins,1989). Os períodos de maior intensidade chuvosa são determinantes para a ocorrência de patógenos tanto no campo de cultivo, quanto em ambientes de armazenamento, pois a umidade relativa do ar, juntamente com a temperatura, são um dos principais fatores ecológicos para a ocorrência de determinadas doenças, sendo comuns na região, por exemplo, a ocorrência de algumas doenças fúngicas, tais como a antracnose (Colletotrichum lindemuthianum), mofo branco (Sclerotinia sclerotiorum) e podridão de raízes (Rhizoctonia solani) (Wendland, et al., 2016).

O experimento foi conduzido no Laboratório de Fitopatologia do Centro de laboratórios (CENLAG) da UFAPE. 
Tabela 1

Sementes crioulas de Vigna unguiculata (L.) Walp coletadas de agricultores familiares ou banco de sementes de cooperativa.

\begin{tabular}{cccc}
\hline $\begin{array}{c}\text { Amost } \\
\text { ra }\end{array}$ & Origem & Fornecedor & Safra \\
\hline 1 & Garanhuns & $\begin{array}{c}\text { Produtora rural do sítio } \\
\text { Cruz }\end{array}$ & 2019 \\
\hline 2 & São João & $\begin{array}{c}\text { Banco de sementes de } \\
\text { cooperativa }\end{array}$ & 2018 \\
\hline 3 & Jucati & Produtora rural do sítio & 2018 \\
& & Neves & \\
\hline
\end{tabular}

Fonte: Elaborada pelos autores

\subsection{Procedimentos metodológicos}

As sementes, adquiridas das diferentes fontes, foram armazenadas no Laboratório de Produção vegetal, em garrafas pet hermeticamente fechadas e mantidas em geladeiras com temperatura ambiente $10^{\circ} \mathrm{C}+/-2^{\circ} \mathrm{C}$. A sanidade das sementes foi avaliada através de blotter test, segundo orientações das Regras de Análises de Sementes (Brasil, 2009). Inicialmente, foi realizada a desinfestação das sementes através da imersão das mesmas em solução de hipoclorito de sódio a $1 \%$, durante 5 minutos. Posteriormente, as sementes foram lavadas 2 vezes em água destilada e em seguida, foram distribuídas sobre duas folhas de papel germitest esterilizados, umedecidas com quantidade de água equivalente a 2,5 vezes a massa do papel não hidratado. A esterilização dos papéis germitest foi realizada utilizando calor úmido sob pressão, através do uso de autoclave e subsequentemente, os papéis foram secados em estufas a $45^{\circ} \mathrm{C}$ com circulação forçada. Em seguida, os papéis, contendo as sementes, dispostas de forma equidistante, foram enrolados e envolvidos por um plástico transparente e mantidos em câmara de germinação (BOD) em temperatura de $25^{\circ} \mathrm{C}$ e fotoperíodo de 12 horas por um período de 8 dias. Após o período estabelecido, as amostras de sementes e ou plântulas foram analisadas em lupa (Modelo Stemi DV4, Marca Zeiss) para confirmar a presença ou ausência de colônias nas sementes. Posteriormente, foram preparadas lâminas de cada colônia diferente 

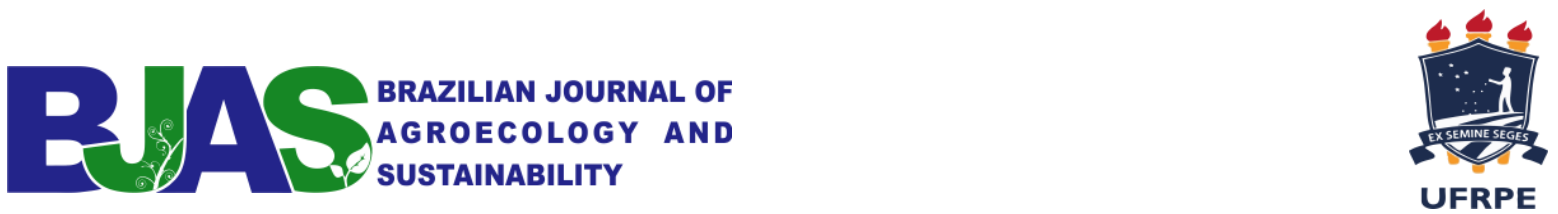

para observação em microscópio óptico (Modelo Lx 300, Marca Labomed) para identificação em nível de gênero.

A partir do levantamento da microflora presente nas diferentes amostras de sementes, as seguintes variáveis foram analisadas:

- Análise qualitativa da infestação de sementes por fungos, em que foram utilizados os dados do total de sementes analisadas por cada gênero de fungo identificado e depois identificada a infestação como sendo alta $(+++)$, moderada $(++)$ e baixa infestação $(+)$. Para os fungos de armazenamento, em que sua infestação é, normalmente mais elevada e mais dificilmente controlada, foram definidos como alta infestação valores superiores a $25 \%$ de infestação; moderada infestação quando apresentava incidência entre 15 a 24\%; e como baixa infestação, as incidências abaixo de 15\%. Para aqueles patógenos de solo ou de campo, agentes causais de doenças em plantas adultas, foram consideradas infestações altas aquelas superiores a $10 \%$; medianas entre 5 e $9 \%$; e baixas, valores abaixo de $5 \%$.

- Porcentagem de sementes contaminadas em cada amostra (independente do gênero de fungo avaliado;

- Incidência (\%) de cada gênero identificado em cada amostra.

O delineamento experimental conduzido foi o inteiramente casualizado, com quatro repetições cada, sendo a unidade experimental composta por 25 sementes. Foram utilizados 3 tratamentos compostos por cada amostra (amostra ou região). A análise de variância e a comparação de médias foi feita pelo teste de Tukey a 5\% de probabilidade, utilizando-se o programa estatístico Sisvar.

\section{RESULTADOS E DISCUSSÃO}

A qualidade sanitária de sementes crioulas coletadas de agricultores familiares na região do agreste de Pernambuco, das localidades de Garanhuns, São João e Jucati, foi analisada qualitativamente e mostrou presença marcante de fungos de armazenamento, pertencentes aos gêneros Aspergillus, com alta infestação e Penicillium e Botrytis com infestação baixa (Tabela 2). Estes, ao contaminarem o feijão na colheita, podem determinar perdas significativas durante o período de armazenamento, comprometendo a qualidade dos grãos, bem como a germinação e o vigor das sementes (Choudury, 1979; Silva et al., 2013). Além disso, podem estar presentes como contaminantes ou na forma de micélios dormentes entre os tecidos do pericarpo ou do 

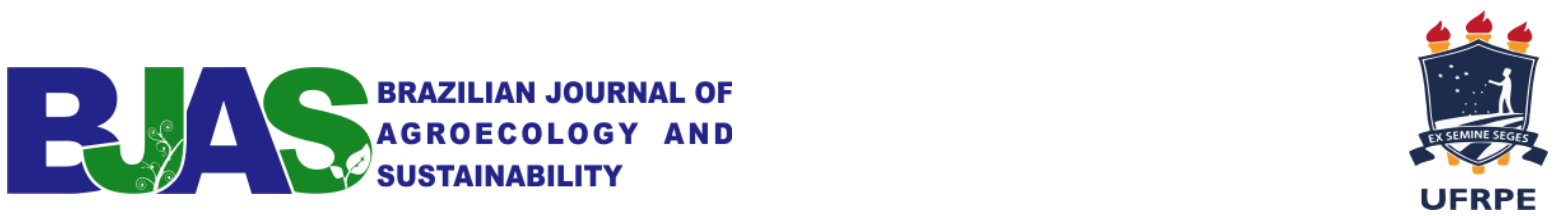

tegumento das sementes, podendo desenvolver-se e causar danos às mesmas (Dhingra, 1985; Machado, 2000). Estes danos incluem alteração da coloração do tegumento, redução do poder germinativo, redução do peso, aceleração da deterioração, produção de toxinas (Choudury, 1979), bem como apodrecimento e morte da semente.

Tabela 2

Avaliação qualitativa da contaminação (total) por fungos nas três amostras de sementes crioulas de feijão de corda

\begin{tabular}{c|c}
\hline Patógenos & Contaminação nas diferentes sementes \\
\hline Aspergillus & +++ \\
\hline Rhizoctonia & + \\
\hline Botrytis & + \\
\hline Alternaria & + \\
\hline Fusarium & + \\
\hline Penicillium & + \\
\hline
\end{tabular}

* alta +++ (acima de $25 \%$ para fungos de armazenamento e acima de $10 \%$ para patógenos de campo e habitantes do solo); moderada ++ (de 15 a 24\% para fungos de armazenamento e de 5 a $9 \%$ para patógenos de campo e habitantes do solo); baixa + (1 a 14\% para fungos de armazenamento e abaixo de $5 \%$ para patógenos de campo e habitantes do solo)

Fonte: Elaborada pelos autores

Nas amostras analisadas, também foram identificados fungos do gênero Fusarium, e Alternaria com baixa infestação e Rhizoctonia com uma infestação mediana, os quais possuem espécies que são responsáveis por causar fusarioses, mancha de alternaria e podridão radicular, respectivamente. $\mathrm{O}$ gênero Fusarium inclui espécies que também podem estar associadas às sementes durante o período de armazenamento (Puzzi, 2000), e inclusive, são responsáveis por vários danos às sementes e pela produção de micotoxinas em grãos (Mallman \& Dilkin, 2007). Já outras espécies, pertencentes ao mesmo gênero, são causadoras de doenças de grande importância econômica, como as fusarioses no feijão que incluem a murcha de fusarium e a podridão radicular. No feijão caupi, a murcha de fusarium está entre as doenças de maior importância econômica e é causada pelo fungo Fusarium oxysporum f. sp. tracheiphilum (E. F. Smith), Snyder e Hansen (1941) e (Crop Protection Compendium [CABI], 2009). 

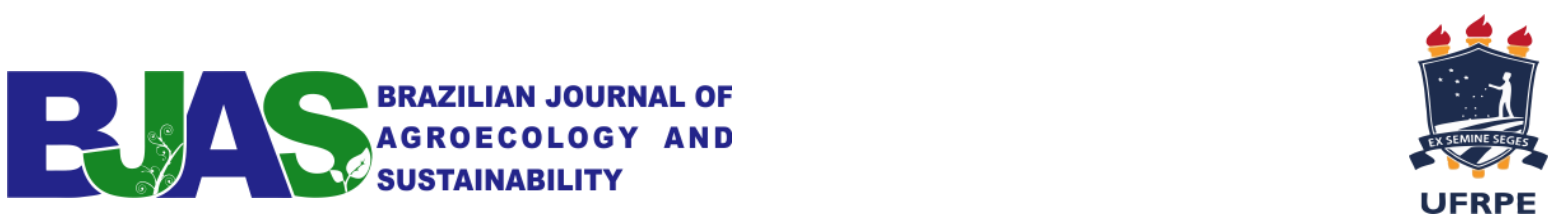

Do ponto de vista epidemiológico, a associação deste gênero de fungo à semente é um dos aspectos mais relevantes para sua disseminação a longas distâncias e pela introdução do inóculo inicial entre regiões de cultivos (Neegaard, 1977; Costa et al., 2003). Vale ressaltar que este é um aspecto de grande relevância no que se refere às sementes crioulas, com as quais se praticam trocas e doações. Dessa forma, manter a qualidade fitossanitária das sementes e por conseguinte, o controle desses patógenos pode contribuir para a não disseminação desta e de outras doenças, principalmente causadas por patógenos de solo. A análise da porcentagem de sementes crioulas contaminadas com algum patógeno, em cada variedade de feijão de corda, revelou que a qualidade sanitária das sementes oscilou bastante de acordo com a amostra analisada, e a incidência de patógenos variou entre 21 a 100\% (tabela 3), sendo a amostra 2 a que apresentou maior contaminação.

\section{Tabela 3}

Porcentagem de contaminação de sementes crioulas de feijão de corda (Vigna unguiculata L.Walp) por patógenos.

\begin{tabular}{cc} 
Amostras & $\begin{array}{c}\text { Porcentagem de contaminação de } \\
\text { sementes (\%) }\end{array}$ \\
\hline 1 & 21 \\
\hline 2 & 100 \\
\hline 3 & 43 \\
\hline
\end{tabular}

Fonte: Elaborada pelos autores

Através de análise quantitativa, foi observado que a incidência dos fungos Botrytis, Alternaria e Fusarium não diferiu entre as amostras de sementes e foi verificada uma variação de 0 a $12 \%, 0$ a $7 \%$ e 0 a $2 \%$, respectivamente para as amostras 1,2 e 3 . Fungos do gênero Penicillium foram responsáveis pela contaminação de 2 e $5 \%$ das sementes das amostras 3 e 2 , respectivamente e não diferiram entre si. Por outro lado, as sementes da amostra 1 não apresentaram nenhuma contaminação por espécies deste gênero, não diferindo apenas das sementes oriundas de Jucati (Tabela 4). 
Tabela 4

Incidência de fungos (\%) associados a sementes crioulas de Vigna unguiculata (L.) Walp de diferentes origens no agreste do estado de Pernambuco.

\begin{tabular}{|c|c|c|c|c|c|c|}
\hline \multirow[t]{2}{*}{ Amostras } & \multicolumn{6}{|c|}{ Patógenos } \\
\hline & Botrytis sp & Penicilium sp & Aspergillus spp & Rhizoctonia sp & Alternaria sp & Fusarium sp \\
\hline 1 & $0 \mathrm{a}$ & $\mathrm{Ob}$ & $3 b$ & $14 \mathrm{a}$ & $2 \mathrm{a}$ & $2 \mathrm{a}$ \\
\hline 2 & $6 a$ & $2 \mathrm{ab}$ & $90 \mathrm{a}$ & $0 \mathrm{~b}$ & $0 \mathrm{a}$ & $0 \mathrm{a}$ \\
\hline 3 & $12 \mathrm{a}$ & $5 a$ & $5 b$ & $13 a b$ & $7 \mathrm{a}$ & $2 a$ \\
\hline C.V. (\%) & 195,0 & 85,71 & 20,10 & 66,7 & 127,6 & 264,58 \\
\hline
\end{tabular}

*Médias seguidas de mesma letra não diferem estatisticamente entre si e letras diferentes diferem entre si, em cada coluna, pelo teste de Tukey a 5\% de probabilidade.

Fonte: Elaborada pelos autores

Segundo Torres e Bringel (2005) a grande frequência de fungos de armazenamento, está relacionada com a idade e com as condições em que as sementes foram armazenadas, tais como umidade, ventilação e outros.

A contaminação por fungos do gênero Aspergillus para as sementes da amostra 2 foi de até $90 \%$, diferindo das demais amostras (Tabela 4). Outro aspecto importante observado nesta amostra foi a ausência de contaminações por Rhizoctonia, Alternaria e Fusarium.

Fungos do gênero Aspergillus são muito comuns na deterioração das sementes, provocando muitos prejuízos, sendo responsáveis por diminuição na germinação e perda de peso e descoloração das sementes, elevação de ácidos graxos, alterações bioquímicas, e produção de toxinas que podem afetar tanto humanos como animais (Silva, 2017; Torres \& Bringel, 2005). No entanto, esse gênero também se caracteriza por sua grande capacidade de produção de metabólitos secundários, o que pode lhe conferir importantes características antagônicas e assim, garantir maior competitividade e, consequentemente a predominância do gênero (Gomez et al., 2007). As análises obtidas neste trabalho mostraram que a alta incidência dos fungos do gênero Aspergillus nas sementes pode ser devido a essa capacidade e, provavelmente, foi um dos fatores responsáveis por inibir o desenvolvimento de outras espécies.

A produção de micotoxina em grãos de feijão, é um aspecto importante a ser observado em sementes com elevada incidência de fungos do gênero Aspergillus. As mais importantes são 

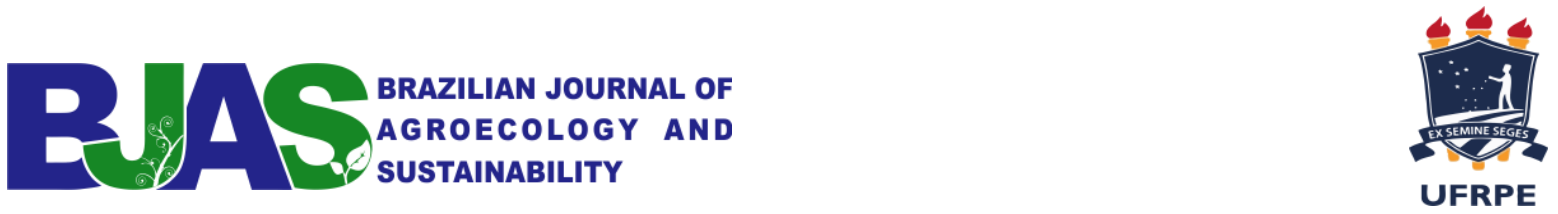

a aflatoxina (A. flavus ou A. parasiticos) e ocratoxina A (A. ochraceus) e ambas podem causar sérios danos à saúde animal ou humana, através da intoxicação alimentar, podendo provocar alterações tóxicas, mutagênicas, teratogênicas ou carcinogênicas, que podem levar a problemas renais, hepáticos, câncer e imunossupressão (Constant et al., 2016; Caldas et al., 2002; Simionato et al. 2003). Em relação às plantas, várias espécies deste gênero causam podridões em sementes, raízes ou colo, diminuindo o percentual de germinação ou causando o damping off em plântulas. Em campo, esses problemas se refletem em desuniformidade de stand, redução do número de plantas por área e, consequentemente, redução na produtividade.

As amostras 1 e 3 apresentaram incidência média de 13 e 14\%, respectivamente para fungos do gênero Rhizoctonia, não diferindo entre si. A amostra 2 não apresentou contaminação por fungos do gênero Alternaria. No entanto, diferiram significativamente apenas da amostra 1.

Os patógenos de solo, que incluem Rhizoctonia e Fusarium causam problemas nas plântulas, como a podridão de suas raízes, o que leva a um quadro de deficiência nutricional, e, consequentemente, causam efeitos indiretos, como necrose nas folhas, amarelecimento, murcha e morte das plantas (Ikram \& Dawar, 2013).

Uma avaliação mais criteriosa, com uma amostra mais expressiva, pode elucidar alguns questionamentos aqui levantados, através dos resultados obtidos, que permitiram trazer à tona para a comunidade científica uma discussão importante e relevante para essa temática, com um grande impacto para o manejo e conservação dessas sementes. Os resultados apresentados aqui mostram que a qualidade sanitária de sementes crioulas deve ser uma preocupação e deve ser analisada preventivamente para evitar disseminação de patógenos no local onde elas estão sendo produzidas e armazenadas ou mesmo a disseminação de alguns patógenos no solo principalmente quando essas sementes estão em bancos de sementes e são distribuídas a diferentes agricultores na região. Dessa forma, políticas públicas de assessoramento técnico para os agricultores familiares bem como parcerias com universidades, institutos de pesquisa e ensino, organizações diversas são importantes para o fortalecimento dessas práticas tradicionais. Vale salientar que os bancos de sementes comunitários representam um resgate cultural das gerações passadas, o fortalecimento da identidade dos agricultores e a garantia da autonomia das famílias, possibilitando a produção de alimentos saudáveis e de qualidade, além da conservação de espécies nativas (Rodrigues et al., 2016). Entretanto, certas espécies de fungos, que podem infectar essas sementes, têm a capacidade de produzir micotoxinas trazendo riscos à saúde de animais e humanos (Ogungbemile et al., 2020; Constant et al., 2016). Assim, o controle sanitário dessas sementes, bem como dos grãos são importantes, do ponto de vista 

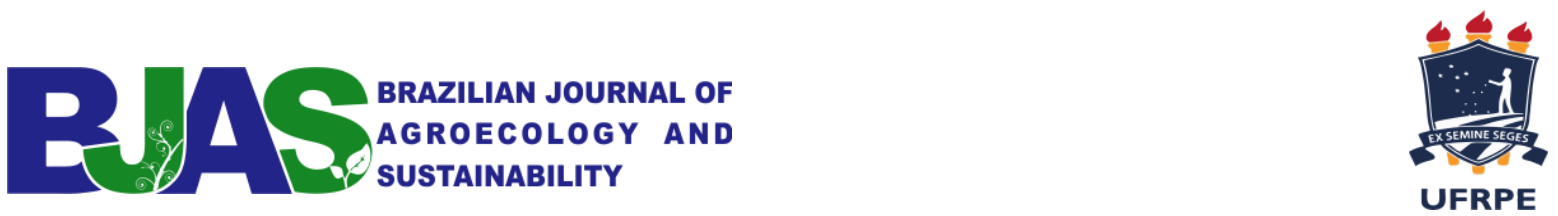

da saúde humana e da segurança alimentar. Ressaltamos ainda a importância de estudos mais detalhados sobre a ocorrência e identificação de patógenos em nível de espécie e em relação à presença de toxinas que podem trazer riscos à saúde humana, de animais e ao meio ambiente, sobretudo em se tratando de sementes crioulas mantidas por comunidades tradicionais.

As sementes crioulas podem ser consideradas símbolos de resistência em lutas em defesa dos interesses dos agricultores familiares perante as grandes multinacionais (Siquieroli et al., 2020) e são consideradas a base da agricultura familiar, representando uma riqueza natural das comunidades e uma importante fonte genética de tolerância às condições ambientais onde são cultivadas, com resistência à pragas e doenças (Silva et al., 2009).

As sementes crioulas de feijão avaliadas neste trabalho apresentaram grau diferenciado de contaminação e vários fatores podem ser considerados nessa análise. Dentre esses fatores, destacam-se as condições de armazenamento das sementes pelos produtores rurais/banco de sementes bem como o processo de beneficiamento das sementes. Esses resultados nos levam a refletir sobre uma importante questão: como realizar o beneficiamento e o armazenamento adequados de sementes crioulas, através de métodos agroecológicos, para manter sua sanidade e sua qualidade fisiológica, uma vez que a baixa qualidade sanitária influencia negativamente na qualidade fisiológica e na produção da cultura. Dessa forma, faz-se necessário a busca por alternativas ecológicas e sustentáveis com biopesticidas, como por exemplo plantas que produzem metabólitos secundários com ação fungicida e antimicrobiana e que não oferecem riscos de desenvolvimento de resistência à microorganismos patogênicos ou riscos ao meio ambiente em contraponto aos pesticidas químicos tradicionais que causam enorme impacto ao meio ambiente (Ogungbemile et al., 2020).

Como essas sementes são produzidas e mantidas por agricultores familiares e /ou banco de sementes, é salutar pontuar a importância do debate e a disseminação de saberes a respeito das sementes crioulas, capaz de proporcionar maior autonomia aos agricultores familiares, baseando-se nos fundamentos e princípios da agroecologia (Siquieroli et al., 2020). Mas há também o risco de disseminação de patógenos importantes através dessas sementes, por vezes de difícil controle ou que podem até inviabilizar a área de cultivo em algumas situações. Além da presença dos bancos, os eventos de trocas de sementes crioulas representam um veículo de disseminação dos saberes sobre a importância de preservação das sementes crioulas pelos agricultores familiares e da sua manutenção (Siquieroli et al., 2020) mas também podem potencializar a disseminação de patógenos se a qualidade sanitária das sementes não for adequada. 


\section{CONSIDERAÇÕES FINAIS}

A semente crioula é um recurso essencial para a agricultura familiar e para os sistemas agrícolas tradicionais. As sementes crioulas de feijão de corda analisadas neste trabalho apresentam qualidade sanitária variável, com alto grau de infestação por fungos relacionados a ambientes de armazenamento inadequados. Devido à importância sócio-econômica, cultural e genética das sementes crioulas, manter uma boa qualidade sanitária, física e fisiológica das sementes, é fundamental para a própria preservação desse patrimônio genético. Nesse sentido, a integração dos saberes entre comunidades de agricultores familiares (guardiões de sementes crioulas) e universidades e institutos de ensino/pesquisa pode representar uma estratégia a ser adotada e incentivada visando a melhoria da qualidade e manutenção desse patrimônio genético e cultural através de estratégias agroecológicas.

\section{REFERÊNCIAS}

Barrocas, E. N., \& Machado, J. C. (2010). Inovações tecnológicas em patologia de sementes: Introdução a patologia de sementes e testes convencionais de sanidade de sementes para a detecção de fungos fitopatogênicos. Informativo ABRATES, Lavras - MG, 20(3), 7475.

Batista, J. F., Santos, L. A. O., Andrade, H. M. L. S., \& Andrade, L. P. (2018). Bancos de sementes como instrumento de conservação da sociobiodiversidade. Cadernos da Agroecologia, 13(1). Recuperado em 09 de setembro de 2020, de http://cadernos.abaagroecologia.org.br/index.php/cadernos/article/view/861

Brasil. (2003). Lei de Sementes. Lei n. 10711 de 05 de agosto de 2003. Recuperado em 10 de setembro de 2020, de http:www.planalto.gov.br/ccivll_03/leis/2003/L.10.711.htm

Brasil. Ministério da Agricultura, Pecuária e Abastecimento. (2009). Regras para análise de sementes. Brasília, DF: Mapa/ACS. Recuperado em 10 de setembro de 2020, de http://www.agricultura.gov.br/assuntos/laboratorios/arquivos-

publicacoeslaboratorio/regras-para-analise-de-sementes.pdf/view

Caldas, E. D., Silva, S. C., \& Oliveira, J. N. (2002). Aflatoxinas e ocratoxina a em alimentos e riscos para a saúde humana. Revista de Saúde Pública, 36(3), 319-323.

Catão, R. M. et al. (2010). Qualidade física, fisiológica e sanitária de sementes de milho crioulo produzidas no norte de Minas Gerais. Ciência Rural, 40(10), 2060-2066.

Choudury, M. M. (1979). Importância da patologia de sementes na produção de feijão. Brasília, DF: Informe Técnico Embrapa Semiárido.

Constant, K. K. et al. (2016). Evolution of aflatoxins levels during storage of Cowpeas (Vigna unguiculata L Walp) Bagged pics containing Lippia multiflora moldenke 

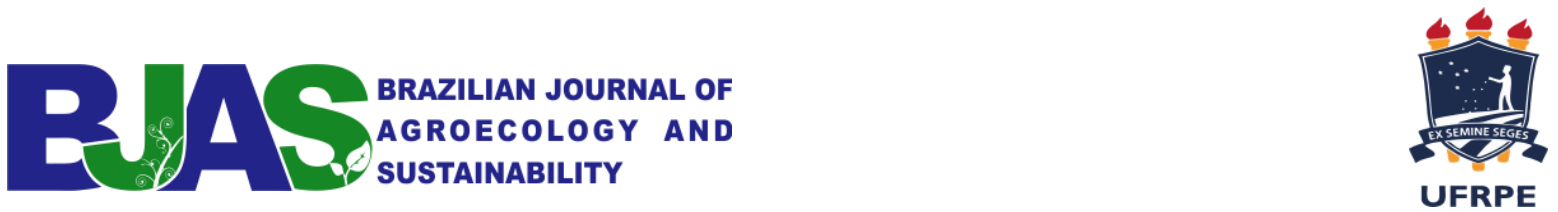

leaves and ivorian exposure risk. International Journal of Science and Research, 5(7), 678-691.

Costa, M. L. N. et al. (2003). Inoculação de Fusarium oxysporum f. sp. phaseoli em sementes de feijoeiro através de restrição hídrica. Ciência e Agrotecnologia, 27(5), 1023-1030.

Crop Protection Compendium. (2009). Wallingfort: CAB International. Recuperado em 10 de agosto de 2020, de https://www.cabi.org/cpc

Dhingra, O. D. (1985). Prejuízos causados por microrganismos durante o armazenamento de sementes. Revista Brasileira de Sementes, Brasília, 7(1), 139-145.

Empresa Brasileira de Pesquisa Agropecuária. (2004). Pesquisa e desenvolvimento em agricultura familiar na embrapa arroz e feijão (16 p.). Santo Antônio de Goiás: Embrapa Arroz e Feijão. Recuperado em 09 de setembro, 2020, de https://www.embrapa.br/busca-de-publicacoes/-/publicacao/213618/pesquisa-edesenvolvimento-em-agricultura-familiar-na-embrapa-arroz-e-feijao

Gomez, E., Piolli, R., \& Conti, M. (2007). Fungal abundance and distribuitions by clearing and lan use in a vertic soil os Argentina. Biology and fertility of soils, Berlin, 43(3), 373377.

Ikram, N., \& Dawar, S. (2013). Effect of Prosopis juliflora (Sw.) DC. in the control of root rot fungi of cowpea (Vigna unguiculata L. Walp.) and mung bean (Vigna radiata L. Wilczek). Pakistan Journal of Botany, 45(2), 649-654.

Jantara, A. E. \& Almeida, P. (2009). Sementes Crioulas: Caminho para Transição Agrocoelógica. Revista Brasileira de Agroecologia, (4), 2.

Leite, N. G. A. (2017). Caracterização protéica do estresse salino em feijão-caupi [Vigna unguiculata (L.) Walp.]. Tese (Ciências Biológicas), Universidade Federal de Pernambuco. Recife, p. 20.

Lima, E. N. (2017). Análise fisiológica, bioquímica e proteômica de respostas ao estresse hidrico em genótipos de feijão-caupi [Vigna unguiculata (L.) Walp.]. Tese (Agronomia/Fitotecnia), Universidade Federal do Ceará. Fortaleza, p. 19.

Lins, R. C. (1989). Áreas de exceção do Agreste Pernambucano (Estudos Regionais, 20). Recife: SUDENE/PSU/SER.

Machado, J. C. (2000). Patologia de sementes: significado e atribuições. In N. M. CARVALHO, \& J. NAKAGAWA (Eds.). Sementes: ciência, tecnologia e produção (4a ed. p. 522-588). Jaboticabal: FUNEP.

Mallman, C. A., \& Dilkin, P. (2007). Micotoxinas e micotoxicoses em suínos. Santa Maria: Edição do Autor.

Martins, A. N. P. et al. (2016). Conteúdo de macronutrientes em cultivares de feijão-caupi [Vigna unguiculata (L.) Walp.]. Anais do Congresso Nacional de Feijão-Caupi, Brasil, 4. 
Neegard, P. (1977). Seed pathology (1187 p., vol. 1). London: The Macmillan Press Ltd.

Ogungbemile, O. A., Etaware, P. M., \& Odebode, A. C. (2020). Aflatoxin Detection and Quantification in Stored Cowpea Seeds in Ibadan, Nigeria. Journal of Biotechnology and Biomedicine, 3(1), 10-17.

Petersen, P. (2013). As sementes das espécies cultivadas são portadoras de mensagens genéticas e de mensagens culturais. Revista Agricultura, 10 (1), 36-45.

Puzzi, D. (2000). Abastecimento e Armazenagem de Grãos (666 p.). Campinas: Instituto Campineiro de Ensino Agrícola.

Rodrigues, C. S. P. et al. (2016). Criação de banco de sementes crioulas para valorização da biodiversidade e garantia da segurança alimentar das comunidades rurais do Velho Chico Rodrigues. Cadernos Macambira, Serrinha, (1), 57-61.

Santos, M. S. (2017). Sementes crioulas: Sustentabilidade no semiárido paraibano. Agrarian Academy, Goiânia, 4(7), 403.

Silva, I. L. et al. (2009). Banco de sementes comunitário Chico Mendes: o resgate da biodiversidade em propriedades familiares vinculadas ao Projeto Esperança/Cooesperança. Cadernos de Agroecologia, 4(2). Recuperado de http://revistas.aba-agroecologia.org.br/index.php/cad/article/view/4539.

Silva, J. F. et al. (2013). Plant extracts for the control the bean weevil Zabrotes subfaciatus (Boheman 1833) (Coleoptera: Bruchidae). Revista Verde de Agroecologia $e$ Desenvolvimento Sustentável 8(3), 1-5.

Silva, T. P. et al. (2017). Sanidade de sementes de feijão-caupi produzidas no cerrado de Roraima em experimento de inoculação de estirpes fixadoras de nitrogênio. Anais Congresso Brasileiro de Agronomia, Fortaleza, CE, Brasil, 30.

Simionato, E. M. R. S, Astray, R. M, \& Sylos, C. M. (2003). Ocorrência de ocratoxina A e aflatoxinas em arroz. Rev. Inst. Adolfo Lutz, 62(2), 123-130.

Siquieroli, A. C. S., Martins, M. P. do C., Pena, D. M. P., \& Silva, A. de A.(2020, maio). Sementes crioulas. Revista em Extensão, Uberlândia, edição especial, 12-22.

Snyder, W. C., \& Hansen, H. N. (1941). The species concept in Fusarium with reference to section Martiella. American Journal of Botany, 738-742.

Torres, S. B., \& Bringel, J. M. M. (2005). Avaliação da qualidade sanitária e fisiológica de sementes de feijão macassar. Caatinga 18(2), 88-92.

Wendland, A., Moreira, A. S., Bianchini, A., Giampson, J. S., Giampan, J. S., \& Lobo Jr., M. (2016). Doenças do Feijoeiro. In L. Amorim, J. A. M. Rezende, A. Bergamin Filho, \& A. Camargo (Eds). Manual de fitopatologia: doenças de plantas cultivadas (5a ed. p. 383-396, vol 2). 


\section{AGRADECIMENTOS}

Ao Cenlag pela disponibilidade de laboratórios e equipamentos, à Pró-Reitoria de Pesquisa e Pós-graduação da UFRPE/UFAPE e aos produtores de feijão e ao banco de sementes pela concessão das sementes crioulas. 